\title{
The Inexplicability of Kant's Naturzweck: Kant on Teleology, Explanation and Biology
}

\author{
by James Kreines (New Haven)
}

\begin{abstract}
Kant's position on teleology and biology is neither inconsistent nor obsolete; his arguments have some surprising and enduring philosophical strengths. But Kant's account will appear weak if we muddy the waters by reading him as aiming to defend teleology by appealing to considerations popular in contemporary philosophy. Kant argues for very different conclusions: we can neither know teleological judgments of living beings to be true, nor legitimately explain living beings in teleological terms; such teleological judgment is justified only as a "problematic" guideline in our search for mechanistic explanations. These conclusions are well supported by Kant's defense of his demanding analysis, according to which teleological judgment literally applies to a complex whole only where teleology truly explains the presence of its parts.*
\end{abstract}

Kant's discussion of teleology, explanation, and biology in the Critique of the Power of Judgment (KU) appears to present stunningly inconsistent answers to even the most straightforward questions. Can biological phenomena be explained in mechanistic terms? Kant seems to answer both "no" and "maybe" - sometimes within the space of a few lines. On the one hand, he claims that "organized beings" cannot

* I refer to Kant's writings from the Akademie edition, Kants Gesammelte Schriften. Ed. Akademie der Wissenschaften. Berlin: de Gruyter, 1900-. Cited by Volume and Page.

All citations not otherwise identified are from Kritik der Urteilskraft, Bd. 5 from the Akademie edition. Translations from Critique of the Power of Judgment. Translated by Guyer and Mathews. Cambridge 2000. Translations occasionally modified.

EE refers to the posthumously published first introduction to the Critique of the Power of Judgment, cited by the Akademie edition Volume and Page. Also translated by Guyer and Mathews.

A/B indicates standard references to Kritik der reinen Vernunft. Ed. R. Schmidt. Hamburg: Felix Meiner Verlag 1956. Translations from Critique of Pure Reason. Translated by Paul Guyer and Allen Wood. Cambridge 1998. Translations occasionally modified.

Archiv f. Gesch. d. Philosophie 87. Bd., S. 270-311

(C) Walter de Gruyter 2005

ISSN 0003-9101 
be explained "in accordance with merely mechanical principles of nature". He includes living beings insofar as he takes this to make impossible "a Newton who could make comprehensible even the generation of a blade of grass". On the other hand, he immediately insists on leaving open the possibility of "mere mechanism" as the "ground" or "origination" of living beings (5: 400). ${ }^{1}$ Is teleology legitimately applicable to biological phenomena? Kant seems to answer both "yes" and "no". On the one hand, organized beings are supposed to be not only mechanically inexplicable but also to require specifically teleological explanation. And Kant claims that our experience of living beings does always suggest the need for teleological judgment (e.g. 5: 366; 5: 386). On the other hand, Kant repeatedly denies that we can legitimately explain (erklären) living beings in teleological terms, and he refers instead to the "inexplicability" of the "natural end" or Naturzweck (5: 395). ${ }^{2}$

Kant's interpreters generally try to resolve these tensions by attributing them to the interference of factors extraneous to Kant's analysis of teleological judgment. Recent interpreters tend in particular to see Kant's analysis as, at least in part, a defense of teleological explanation in biology. Some say that Kant only seems to deny such a role for teleology, because he is independently committed to an artificially narrow use of the term "explanation" (Erklärung). ${ }^{3}$ Some say that Kant only doubts the legitimacy of teleological explanation because he makes outdated assumptions about intelligent design; others more recently say that Kant means to defend teleology by questioning just such assumptions. ${ }^{4}$ And some argue that Kant's independent ambitions to address problems concerning freedom and morality in the $\mathrm{KU}$ require

${ }^{1}$ Citations in the text not otherwise identified are from KU; for references to Kant's works, see my list of abbreviations below. In this passage, the "mere mechanism" is missing in the Cambridge translation. See also (5: 418).

2 For example: "teleological judging is rightly drawn into our research into nature [...] without presuming thereby to explain it (ohne sich anzumaßen sie darnach zu erklären)" (5: 360; Kant's emphasis). "Positing ends of nature in its products [...] belongs only to the description of nature (Naturbeschreibung)" but "provides no information at all about the origination and the inner possibility of these forms, although it is that with which theoretical natural science is properly concerned" (5: 417; see also 5: 411).

3 See especially Zumbach 1984, e.g. 123.

${ }^{4}$ For the former approach, see MacFarland 1970, 106 and 111; for the latter, see Zumbach 1984, 12; Allison 1991, 33-4; Warnke 1992, 45; Ginsborg 1997, 2001 . 
him to make claims about living beings which are unsupported by his own analysis. ${ }^{5}$

Though I am indebted to recent interpreters on a number of points, I argue for a very different overall account. Kant consistently claims that we can never legitimately explain living beings in teleological terms. This claim is absolutely central to his undertaking, and does not create a tension within Kant's account which needs to be explained away. On the contrary, Kant is arguing for the existence of what is supposed to be a very real tension: on the one hand, our experience of living beings inevitably suggests to us a form of teleological judgment which is indispensably useful; on the other hand, such teleological judgment carries strong explanatory implications which render it problematic. Furthermore, Kant's conclusions emerge directly from his analysis of teleological judgment in a tightly unified line of argument. This analysis, properly understood, cannot be married to any claim that we may legitimately employ some form of teleological explanation to account for living beings. Finally, there is nothing obsolete about Kant's argument and conclusions specifically concerning teleology, explanation and biology. Alternative contemporary accounts require the rejection of one or another of Kant's central premises, and this carries real philosophical costs. Or so I will argue.

Kant's overall argument is unified and driven throughout by recognition of a crucial peculiarity of teleological judgment. Appreciating this peculiarity requires noting that Kant does not think that explanation (Erklärung) is a purely pragmatic or subjective notion. That is, he does not think that an account qualifies as explanatory solely in virtue of describing an explanandum in a way which addresses the pragmatic interests or subjective point of view of a specific audience. Explaining something must always involve some way of getting at why it is as it is, or why it happens as it does - some way of getting at the real underlying causes or determining factors. I will mark this point by saying that Kant holds an "objective" notion of expla-

\footnotetext{
${ }^{5}$ See especially Zanetti 1995 , 49. It is true that Kant aims to draw conclusions concerning practical philosophy. But this ambition is not itself responsible for the tension: Kant argues on grounds specifically concerning teleology and biology that teleology and mechanism conflict in a way that rules out the possibility a role for teleological explanation in empirical science. See also Guyer 2001a, 383, who stresses Kant's moral argument, but also notes the argument internal to Kant's discussion of teleology and biology for the problematic status of teleological judgment of nature.
} 
nation. ${ }^{6}$ Now it does not seem natural to associate judgment generally with explanation: generally speaking a judgment " $\mathrm{S}$ is $\mathrm{P}$ " would be true if and only if S can truly be described as $\mathrm{P}$, and it would be irrelevant whether $\mathbf{P}$ explains $\mathbf{S}$ or vice-versa. But Kant's argument is driven by the recognition that a teleological judgment " $\mathrm{M}$ is for $\mathrm{E}$ " implies more than just that $\mathrm{M}$ can be truly described as benefiting $\mathrm{E}$; it implies that the benefit to E explains $\mathrm{M}$. And what is important about this for Kant's argument is not any requirement it might impose on how $\mathrm{E}$ and $\mathrm{M}$ appear given particular subjective perspectives or pragmatic interests. What is crucial is the requirement that $\mathrm{M}$ really occurs specifically for the sake of E, or that the benefit to E plays some real role in causing, determining or bringing about $\mathrm{M}^{7}$

This principle connecting teleological judgment and explanation drives Kant's initial argument that mere relations of benefit do not themselves justify the application of the concept of a Naturzweck (section 1). And this principle is built into Kant's requirement that a true Naturzweck would have to be an organized being (section 2). The same principle opens up the space for Kant to claim that actual living beings appear to us to be mechanically inexplicable Naturzwecke while denying that we can know them to be such (section 3). And the same principle lends real philosophical strength to Kant's argument that a truly organized being would have to originate in a concept, blocking any possibility of empirical knowledge of real organization in nature (sec-

${ }^{6}$ I do not mean to suggest that there is some other "subjective" type of explanation, but to capture a commitment concerning the nature of explanation generally. As will be clear below, this commitment does not exclude contextual variation. Nor do I mean to say that addressing pragmatic interests somehow disqualifies an account from being explanatory, only that this in itself is not sufficient. Kant himself raises the possibility that "subjective principles" might lead us to judge in teleological terms an object whose "explanation" (Erklärung) would require not teleology but rather mechanism (EE 20: 218). See also MacFarland's (1970, 95 note 1) reading of Kant's use of Erklären in the KU as "objective explanation". And also Kitcher's $(1986,213)$ contrast between Kant and anti-realist "followers of Mach and Duhem": "Kant's proposal [...] is that there is an objective notion of scientific explanation".

7 My formulation of the peculiarity of teleological judgment is heavily indebted to Wright's "etiological" analysis (1975, 24; see also 81). As discussed below, Wright argues from here to conclusions very different from Kant's. Compare also Garrett 1999, 310, on earlier modern treatments of teleology: "Teleology is the phenomenon of states of affairs having etiologies that implicate, in an explanatory way, likely or presumptive consequences of those states of affairs. No proposed teleological explanation, no matter how compelling, can be correct unless it cites an actual example of teleology" (my emphasis). 
tion 4). With this unified line of argument in hand, we can understand why teleological judgment is both justified (in virtue of a crucial role guiding the scientific investigation of living beings) and yet also inevitably problematic (in virtue of its explanatory implications) (section 5). Interpreters often see Kant as denying the principle connecting teleological judgment and explanation, because they see this as the only way to eliminate a tension internal to Kant's analysis. I argue that these readings are mistaken (section 6), and that Kant intends the tension specifically to limit the status of teleological judgment of nature and to prevent any intrusion of theology into empirical science (section 7). And Kant's denial that there can be any room for teleological explanation in any empirical science is not contradicted or even mitigated by the solution of the "Antinomy of the Teleological Power of Judgment" (section 8). I conclude by showing that Kant's analysis is incompatible with contemporary defenses of function explanation in biology, but has philosophical strengths of its own (section 9).

Finally, the interpretations I criticize may well be motivated by charity to find in the KU currently popular lines of thought - a defense of teleological explanation similar to contemporary forms of nonreductive physicalism, an appeal to the multiple realizability of functions, etc. ${ }^{8}$ I embrace the goal of charity, but argue that it is not well served in this case. For I argue that these contemporary views fit poorly with Kant's arguments, so that introducing them can only muddy the philosophical waters. Furthermore, philosophical views generally tend to have weaknesses as well as strengths, and it is hardly charitable to burden Kant with any weaknesses of contemporary views which his own approach need not share. Charity is crucial if we are to discover and understand the lasting philosophical importance of figures in the history of philosophy. But charity should not mean that we seek to interpret Kant's conclusions so that they are as near as possible to those favored by contemporary tastes. It should mean rather that we seek to understand the real philosophical strengths of Kant's arguments - even and especially where those arguments support conclusions which challenge contemporary tastes, and so promise to broaden our understanding of the fundamental philosophical possibilities. That, in any case, is the charity I aim for here.

\footnotetext{
8 E.g. Zumbach 1984, 91 and 112 note 23; Meerbote 1984; Ginsborg 2001, 247 and 256 note 18
} 


\section{Why Relative Purposiveness Does Not Justify Teleological Judgment}

Kant begins the "Critique of the Teleological Power of Judgment," with an analysis of the teleological judgment of natural phenomena, or - in his terms - of the concept of a Naturzweck ("natural end" or "natural purpose"). It is crucial to avoid the common but mistaken view that Naturzweck is just Kant's "expression for biological organisms" that were so, then Kant would merely be analyzing an empirical concept like living being or organism, which (by his own lights) could not result in an extension of our knowledge but merely the clarification or explication of the concept. If we go down this path then Kant will seem to be trying to dictate by means of conceptual analysis how actual living beings must be - an unlikely undertaking for the philosopher who broke with traditional metaphysics precisely by denying the possibility of cognizing objects "through mere concepts" (Bxiv). ${ }^{10}$ What Kant proposes instead is an analysis of the conditions under which a teleological judgment would be true specifically of a natural being. The corresponding concept of a Naturzweck is constructed to apply by definition to anything which meets those conditions. Kant will also consider the degree to which this analysis applies to actual living beings, and so the degree to which it makes sense to judge them in teleological terms or to judge them to be Naturzwecke. It is impossible to understand Kant without distinguishing the analysis and its application; his basic point will be that the proper analysis of teleological judgment carries such strong implications that its application to nature is bound to be problematic.

It is worth proceeding carefully with Kant's initial steps, as they contain often unnoticed keys to his conclusions. This is particularly true of Kant's consideration in $\S 63$ of relations of benefit between the parts of nature, or "relative purposiveness". Kant proposes an example in which a sea shrinks from its shores, leaving behind sandy soil which benefits the subsequently flourishing forest of pine trees $(5: 367)$. There

\footnotetext{
9 Zumbach 1984, 19. See also MacFarland 1970, 102. Many others take Kant to be analyzing the concept or the real features of actual living beings without explicit note. I am following the most notable exception: McLaughlin's careful and persuasive treatment (1990, especially 46-7). See also Wood 1999, 219. The analysis and its application are intertwined in the text, as Kant himself notes (5:371).

10 See also A5-6/B9-10, and compare Zumbach 1984, 139, and MacFarland 1970, 97. Kant's continuing commitment in the KU to this touchstone of the critical philosophy can be seen, for example, in his discussions of "mere logic" (EE 20: 204 and 211-2 note).
} 
may well be some reason to judge sea, sand and trees in teleological terms. But the benefit to the trees does not itself provide such a reason. If it did, then there would be reason to judge in teleological terms any and everything in nature which happens to benefit something else. But that would be absurd: benefit cannot be a reason for teleological judgment of natural phenomena which make possible human life in arctic conditions, for "one does not see why human beings have to live there at all" (5: 369). The question is, then, how to avoid such absurd consequences in a non-arbitrary way? How to give principled reasons why relations of benefit should fall short of justifying teleological judgment?

Kant's solution turns on the connection between teleological judgment and explanation. The fact that changes in one thing benefit another gives us no reason to doubt that these changes can be explained perfectly well without reference to benefit or beneficiary, and so no reason to think anything happens because of a function, purpose, end, etc. ${ }^{11}$ And that is why relations of benefit give us no reason to judge natural phenomena in teleological terms. Taking benefit to justify such judgment would be "bold and arbitrary," specifically because of its explanatory irrelevance: "for even if all of this natural usefulness did not exist, we would find nothing lacking in the adequacy of natural causes for this state of things" (5: 369). For example, teleological judgment of the movements of sand and sea might be justified if these could not be explained "without ascribing an end" (ohne [...] einen Zweck unterzulegen) (5: 368). But the mere benefit of sea and soil to the trees gives us no reason to doubt that these movements can be explained perfectly well without any reference to the pine trees or to any purpose at all. In Kant's terms, such "relative purposiveness" "justifies no absolute teleological judgments" (5: 369). In other words, it does not justify the literal application of the concept of a Naturzweck. The relation of benefit suggests only a purposiveness which is "contingent" or extrinsic to the sea; it is merely "external purposiveness" (äußere Zweckmäßigkeit) (5: 368). Grasping the conditions which would justify teleological judgment of natural beings will require making sense of a contrasting sense of intrinsic or internal purposiveness (innere Zweckmäßigkeit). ${ }^{12}$

11 See Kant's own stress on darum and weil at (5: 369).

12 It is crucial that Kant is not just arguing that sea and sand belong to a non-teleological class of things (as in MacFarland 1970, 99). In fact, Kant's introductions provide other grounds for thinking that all of nature must be judged in teleological terms. Kant's point here concerns not different things but different possible grounds for teleological judgments; see especially McLaughlin 1990, 43. Mistaking this point can lead to a misunderstanding of Kant's claim that relative pur- 
Note the indispensable role played in Kant's solution by both the objective notion of explanation and the peculiarity of teleological judgment. First of all, say we grant that relations of benefit give us no reason to doubt that an event can be explained in non-teleological terms. If you held a purely pragmatic notion of explanation, you might still say that benefit suggests a role for teleological explanation: the existence of benefit shows that there is indeed another available description of the event which might well address a different set of pragmatic interests concerning it. Kant reasons differently: if benefit gives us no reason to doubt that a natural event occurs because of causes having nothing to do with purposes or ends, then it would be "bold and arbitrary" to take this benefit itself as reason to think this very same event can also be explained by a purpose or end. Furthermore, say we grant this first point, accepting that relations of benefit do not themselves suggest any role for teleological explanation. This still presents no problem with describing the movements of the sea and the sand in terms of their benefit to the forest. So why should this present a problem for teleological judgment? Only because teleological judgment never just describes, but always implies an explanation.

\section{The Organization Condition}

Kant proceeds on the basis of his discussion of relative purposiveness to argue that a Naturzweck would have to be an organized being. This 'organization condition' (as I will call it) requires that the whole system determines its parts, in the sense that the parts are present specifically because of their purposes or functions within the whole.

This organization condition is only the first of two parts of Kant's analysis; by itself it defines only the general concept of an organized being, or a Zweck ("end" or "purpose") - not yet the concept of a natural

posiveness depends on internal purposiveness because only a true Naturzweck could be benefited. Kant's point is not just to propose a division between the types of things which can and cannot be benefited. Kant's main challenge in $\S 63$ is to provide an argument to justify the claim that mere relations of benefit themselves fall short of grounds to judge nature in teleological terms, or to consider something (e.g. the system of sand, sea and trees) to be a Naturzweck. Only with that argument in hand can he draw the further consequence that even the existence of real relations of benefit will require that some parts of nature (e.g. the trees) satisfy stronger requirements which better justify the application of teleology. 
organized being or a Naturzweck in particular. In fact, Kant tends to explain this first requirement by demonstrating how it is met in the specific case of non-natural artifacts, such as a house or a watch (5: $372 \mathrm{ff}$.). To elaborate on Kant's example, consider a spring in a watch. As with the movements of sea and sand, there is a sense in which the behavior of the spring itself can be explained in non-teleological terms: the spring behaves as it does because of its own material constitution and shape. But this spring might have been constructed differently so as do to virtually anything: to break when wound, to turn the gears at speeds varying with the temperature, to make squeaking noises, etc. As Kant says later, "nature, considered as mere mechanism, could have structured itself differently in a thousand ways without hitting on precisely the unity in terms of a principle of purposes" $(5: 360) .{ }^{13}$ And this makes room for teleological explanation, specifying that the spring and the other parts of the watch are present specifically on account of the determinate and coordinated functions they are to fulfill within the organized whole.

In the case of non-natural artifacts, such as a watch, the organization of the whole determines the parts only via human design. But this particular aspect of such examples is not itself crucial specifically to Kant's claim that teleology would be justified by organization as opposed to mere benefit or relative purposiveness. What is crucial is only that the functional organization of the whole (in some way or other) determines the parts - or that the presence of the parts is (in some way or other) determined by their functions within the organized whole. In terms of Kant's official statement of the requirement, "for a thing as Naturzweck it is requisite, first, that its parts (as far as their existence and their form are concerned) are possible only through their relation to the whole" (5:373). ${ }^{14}$

Note how this requirement follows specifically from Kant's treatment of relative purposiveness. Mere benefit does not justify teleological judgment, because it provides no reason to doubt that the benefit

13 This passage actually concerns the more complicated case of living beings. Another way of putting the point: in an organized system there is a "contingency of form (in relation to the mere laws of nature)" (5: 396). Compare Wright 1976, $73-83$.

${ }^{14}$ Kant goes on to connect this requirement to his argument that the only way to make comprehensible such determination of the parts by the whole is to think of the system as the product of an idea representing the whole. But the point of the organization condition itself is independent of this further argument, which I discuss below. 
itself is just an accidental consequence of non-teleological causes. So Kant's analysis must rule out the possibility that the parts of a system are present for some other reason, and happen by chance to benefit the whole by fulfilling functions. Thus the analysis must require that the parts of the system are not present for other reasons - they must be present specifically on account of functions within the whole, or "possible only through their relation to the whole". This is to build the objective notion of explanation into the analysis of teleology. And this results in a demand far stronger than any requirement that a system be 'organized' only in the sense that it currently has a structure or form which meets some standard (e.g. is sufficiently complicated, regular, or appears to us in a particular light). For any requirement of the latter sort, no matter how demanding, could be conceivably be satisfied by a system whose parts happen by chance to have come together with the required structure or form.

As mentioned above, Kant's first requirement is not enough by itself for an analysis of the concept of a Naturzweck. For one way this first requirement can be met is the way it is met in the case of artifacts, which are non-natural in that they are the products of our own design. So Kant needs a second requirement in order to rule out artifacts and narrow the analysis. He needs to narrow his analysis of organized beings generally (including those organized by the action of an external designer) to an analysis of naturally "self-organizing" (5: 374) beings. Or, he needs to narrow this analysis of Zwecke in general to come up with an analysis of Naturzwecke in particular. Kant seeks to do this by means of a second requirement again governing the relations between whole and parts. Considered in these terms, ruling out non-natural products of design means ruling out the mere imposition of an organizational form or structure onto parts by the work of "a rational cause distinct from the matter" $(5: 373)$. To exclude the possibility that the form or structure is imposed from the outside is to require that it is imposed from within. And considered in terms of part/whole relations this means that the parts themselves must be responsible for the organized form of the whole.

Kant's own gloss on this second requirement is difficult to follow because it effectively combines the force of both requirements into a single statement. Kant says: "it is required, second, that its parts be combined into a whole by being reciprocally the cause and effect of their form" (5: 373). To begin with, the functional organization of the whole must not be merely imposed by an external designer, but rather determined by the parts themselves. But the first requirement already 
demands that the presence of parts of a particular type or form must also depend on the functional organization of the whole. So, drawing both points together, the parts would have to be both cause and effect of their own form.

It is imperative that we not confuse the content of this highly abstract analysis with Kant's discussions of how the analysis applies to actual living beings - for example, Kant's attempt to "elucidate" the analysis by discussing its applicability to three features of trees: they have parts which mutually compensate to preserve the whole, they incorporate matter to grow, and they reproduce (5: $371 \mathrm{f}$.). ${ }^{15}$ Kant's applications of the analysis are a complex topic in their own right, to which we must carefully attend as we proceed. But concerning the abstract analysis itself, the most important thing to note is a puzzle concerning how its conditions could possibly be jointly met. For the two requirements appear to conflict: the first requires that the parts are determined by the whole; the second requires that the whole is determined by the parts. ${ }^{16}$

This puzzle is especially important here because recent interpreters tend to see it as reason to give a reading of Kant's first requirement that is very different than mine. In particular, Kant's view is often supposed to be this:

(a) Actual living beings are Naturzwecke, or systems in which the parts seem to us to be present on account of functions within the whole.

Interpretation (a) substantially weakens Kant's first requirement, so that it demands only that the whole seems to determine the parts; and this would not conflict with the second requirement that the parts really do determine the whole, thus resolving the puzzle. But I will argue for a very different placement of the 'seem to us,' and so attribute to Kant a very different view, namely:

15 Interpreters who take Naturzweck to be the empirical concept organism tend to mistake these three features for part of the content of Kant's analysis and/or for an explanation of why actual organisms are not supposed to be mechanically explicable (e.g. Zumbach 1984, 24-26). But Kant himself says that the three features are meant to "elucidate" an analysis he has not even completely stated at this point (5: 371); see especially McLaughlin 1990, 46-47. And see Ginsborg's (2001, 255 note 10; and 2004) persuasive arguments that Kant's important claim for mechanical inexplicability follows from the first requirement, not from these observations about what distinguishes living beings from artifacts. I will return to this passage below.

16 Ginsborg 2001, 236 and 251, gives a nice formulation of the puzzle and defense of its difficulty and importance; I argue for a different resolution below. 
(b) Actual living beings seem to us to be Naturzwecke, or systems in which the parts are present on account of functions within the whole.

According to (b), Kant's analysis does include the full-strength organization condition, or the requirement that the whole really does determine the parts. In other words, the "seems to us" is not part of the content of Kant's analysis of the concept of a Naturzweck, but part of this position on the applicability of this concept to living beings. I have already argued above that it is (b), and specifically the full-strength organization condition, which follows from Kant's treatment of the merely external purposiveness of benefit (as in cases like the sea, sand and trees). I will continue to argue that (b) is the correct reading, and that the same full-strength organization condition does a remarkable amount of philosophical work throughout Kant's account, lending real support to conclusions that can otherwise seem to be inadequately defended and even mutually inconsistent. I'll then return to discuss in more concrete terms the point of Kant's second requirement and the puzzle of its relation to the first.

\section{The Mechanical Inexplicability of the Naturzweck}

The full-strength organization condition makes it easy to understand Kant's claim for the mechanical inexplicability of Naturzwecke. This claim does not directly concern actual living beings, but rather the constructed concept of a Naturzweck. And mechanical inexplicability is built right into this concept. More specifically, Kant uses "mechanism" to single out accounts which explain entirely without reference to any special organization, structure, or arrangement of whole systems. So mechanism applies to complex systems where the structure and behavior of the whole is completely determined by the independent changes of the parts. But Kant defines Zweck as the concept of something of which this cannot be true: the whole cannot be explained completely in terms of the independent changes of the parts, for the parts themselves are only present because of their roles within the organized whole. Thus the very concept of a Zweck itself rules out mechanical explicability:

If we consider a material whole, as far as its form is concerned, as a product of the parts and of their forces and their capacity to combine by themselves [...] we represent a mechanical kind of generation. But from this there arises no concept of a whole as a Zweck. (5: 408) 
Again, this claim concerns Kant's abstract analysis, and in particular the general concept of a Zweck, or any sort of organized being at all. This claim for mechanical inexplicability is not directly about actual living beings, and in no way concerns the features which distinguish them from artifacts. ${ }^{17}$

We can also understand in these terms how Kant recognizes a sort of compatibility while also holding that teleology and mechanism are fundamentally incompatible. The example of the spring in the watch highlights the compatibility. If we want to explain the current behavior of the spring, considered in isolation, then we can explain in mechanistic terms. Given a spring of this sort, it will respond to surrounding conditions without consideration of any special whole - it will respond just as a piece of such metal with the same shape and internal constitution would respond anywhere. Nonetheless, teleology can explain something else, namely, why a spring with just these mechanical properties is present within the whole watch. This is one sense in which Kant refers to the "subordination" of mechanism to teleology as "means" to an end (5: 414).

But mechanism and teleology are nonetheless fundamentally incompatible when applied to one and the same complex system (such as the whole watch). When so applied, both purport to account for the origin of the system. To be sure, there can be distinct but compatible explanations of this origin: two different accounts could both explain in virtue of providing information about different portions or aspects of the complete causal history of one system. This is a sense in which explanation can vary in context of the different explanatory interests we might have. But it is crucial that teleology and mechanism, as analyzed by Kant, cannot be compatible in this way. For teleology and mechanism are conflicting ways of characterizing the complete explanation of the origin of the system. Teleology requires that, whatever the details might be, the parts turn out to be present specifically because of functions within the whole. Mechanism requires that, whatever the details, functions or purposes within the whole play no real role in determining the form and presence of the parts: the system must be "the product of the parts and of their forces and their capacity to combine by them-

17 Also: "that a thing is possible only as a Zweck, i.e. that the causality of its origin must be sought not in the mechanism of nature" $(5: 369)$. See especially Ginsborg $2001 ; 2004$. On the distinction between mechanism in this sense and causality generally, see also McLaughlin 1990, 152f., and Allison 1991. Compare also Garrett 1999, 310, on mechanism in earlier modern philosophy. 
selves", or independently of any relation to an organized whole (5: 408; my emphasis). And that is why Kant correctly concludes that we cannot compatibly apply both teleology and mechanism to one and the same natural system; we cannot consider one and the same thing both to be and not to be a Zweck, specifically because "one kind of explanation excludes the other" $(5: 412)^{18}$.

What does this mean about actual living beings? Only that if they are natural organized beings, or Naturzwecke, then they cannot be explained in mechanistic terms. For example, Kant says, "if I assume" that a maggot "is a Naturzweck, I cannot count on a mechanical mode of generation for it" $(5: 411)^{19}$. Yet Kant also leaves open the possibility that the ground of the generation of actual living beings is "mere mechanism" (5: 400; $5: 418)$. The reason for this is strikingly simple, though it is usually obscured by the confusion between the constructed concept of a Naturzweck and the empirical concept living being. Kant simply denies we can know that living beings really are Naturzwecke. When one draws upon the "problematic" concept of a Naturzweck, Kant says, "one does not know whether one is judging about something or nothing" (5: 397).

There are passages some interpret as conflicting with this denial of knowledge of actual Naturzwecke; I will argue for alternative interpretations of these passages below. But the first and most pressing difficulty concerning Kant's denial is this: how could Kant possibly rule out knowledge of Naturzwecke, given his claims that actual living beings really do seem to fit the analysis? Why shouldn't the fact that living beings consistently appear to meet both Kant's requirements be a perfectly good reason to think that they really are Naturzwecke? The answer turns again on the full-strength organization condition. Certainly Kant thinks that living beings appear to be organized; their form appears to us as completely undetermined by mechanical laws governing the matter out of which they are composed; the fit between their parts is so great that those parts seem as if they must be present in order to fulfill coordinated purposes within the whole. Living beings thus

18 See also 5: 425f. and Zanetti 1995, $50 \mathrm{ff}$. I argue below that Kant's solution to the antinomy does not contradict or mitigate this fundamental incompatibility.

19 Also, mechanism must "always be inadequate for things that we once acknowledge as Naturzwecke" (5: 415). Note that is not an assertion that we can know living beings to be Naturzwecke, as this would mean we could know of limits to our ability to explain in mechanistic terms; yet this same passage insists that we "do not know how far the mechanical mode of explanation that is possible for us will extend" (5: 415). 
present a case in which "experience leads (leitet) our power of judgment" (5:366) to the concept of a Naturzweck, or a case in which the need for teleological judgment is "suggested (veranlaßt) by particular experiences" (5:386). But to really be organized requires more than this - more than a special current structure or form. It requires that the parts really are present specifically because of their functions within the whole. Thus we could know something to be a Naturzweck only if we could really explain part in terms of whole. And Kant will argue that we can never have insight into such explanations of nature, so that our experience "exhibits" but nonetheless cannot "prove" the existence of natural organized beings or Naturzwecke (EE 20: 234).

\section{Intelligent Design, and Why We Cannot Know Living Beings are Naturzwecke}

Kant's argument against the possibility of knowledge of Naturzwecke turns on his claim for a connection between the Naturzweck and intelligent design. As noted above, this claim has found few friends among recent interpreters: some see it as an outdated and mistaken assumption about living beings, others as an assumption Kant himself questions. But we are in a position to appreciate that Kant's analysis does indeed justify the claim he does indeed advocate: insofar as a Natur$z w e c k$ had a genesis we can make comprehensible at all, this would have to be an origin in a concept of the whole system. It is crucial that this in no way implies the reality of intelligent design, for the argument directly concerns not actual living beings but rather Kant's constructed concept of a Naturzweck.

Kant's argument addresses a familiar problem concerning backwards causation to his own requirement that the functional organization of a whole must determine the parts. ${ }^{20}$ For example, assume for the moment that circulation of the blood is the purpose or function of the heart. The beating of the heart would have to be the cause, and circulation of blood will have to be among its effects when present within a whole body. But before the presence of the cause within the whole sys-

20 MacFarland 1970, 106, stresses the backwards causation problem, but the argument is far better than he recognizes here. See also Zuckert 2000, ch. 2, and Guyer 2001a, 383; and 2001b, 265, on backwards causation. And see Spinoza's (Ethics Part IV Preface) similar treatment of the house example, itself central to Aristotle's discussions of teleology (e.g. Physics II.9). 
tem there can be no such effect. And the effect cannot travel back in time to bring into place its own cause; it cannot directly cause its own cause. More generally, before the parts of a system are present, there can be no functioning whole. So the not-yet-existent functional organization of the whole cannot itself travel back in time in order to cause or determine the presence of the parts; it cannot directly cause its own causes. As Kant says, "it is entirely contrary to the nature of physicalmechanical causes that the whole should be the cause of the possibility of the causality of the parts" (EE 20: 236).

The only solution, Kant argues, is that the system must be the product of a prior concept of the whole. Kant argues by means of an example:

The house is certainly the cause of the sums that are taken in as rent, while conversely the representation of this possible income was the cause of the construction of the house [...] The first could perhaps [...] be called the connection of real causes, and the second that of ideal, since with this terminology it would immediately be grasped that there cannot be more than these two kinds of causality. (5: 372f.)

In the order of "real causes" the effect cannot precede and so explain the cause; thus it can only do so as "ideal," or as represented by a prior concept. Applied to complex systems: in the order of "real causes," effects of the parts within a functioning whole cannot precede and so explain the presence of those very parts; thus they can do so only as "ideal," or as represented by a prior concept. So the only conceivable genesis of a truly organized being would have to be an originating idea or concept of the whole and the roles to be played by the parts (5:393; 5: 407f.). This argument licenses Kant to proceed to link his statement of the organization condition directly to the requirement that the whole has an origin in "a concept or an idea that must determine a priori everything that is to be contained in it" (5:373).

The best way to appreciate the strength of Kant's argument here is to identify three key premises on which it rests. To begin with, the argument clearly draws on the premise that (i) there is a unidirectional order of "real causes" in time. The argument does not require any more specific commitments about causality and explanation which Kant may otherwise hold, such the idea that explanation must always have the form of a strict deduction of effects from general causal laws and prior conditions. ${ }^{21}$ The argument requires only that a single direction of time

${ }^{21}$ See especially Zumbach's view of the role of this more specific commitment (1984, 95-7 and 123). 
prevents effects themselves from directly bringing about or determining their own causes, and so prevents effects from directly explaining why their own causes occur.

A second premise turns on the idea that the analysis of the concept of a Naturzweck must build in the objective notion of explanation, placing constraints on the actual determination or causal history from which a complex system originates. Kant's argument would indeed be weak without this premise, or if the concept of the Naturzweck constrained only the current structure or form of a system. For no matter how interesting or complicated a current structure or form might be, it can still fail to be the product of a concept or idea. ${ }^{22}$ Kant's more specific premise (ii) is the full-strength organization condition: in a Naturzweck the functional organization of the whole must determine the presence and form of the parts.

Now it is true that some contemporary philosophers propose that natural selection can also explain in precisely this required sense - can explain the presence of the parts of living beings in terms of their functions - without any appeal to intelligent design. ${ }^{23}$ But, first, this contemporary "etiological" approach is controversial. Its contemporary critics charge that any notion of function purporting to account for the presence of parts will inevitably carry some implication of intelligent design, which will be inappropriate in an interpretation of natural selection. ${ }^{24}$ Second, the etiological approach to functions requires a very different analysis of the conditions under which such functions apply. In particular, it must specifically require the repeating process of reproduction of complex individuals within a larger biological species. Only this makes possible the claim that the heart (for example) is present on

22 Some readings of Kant's argument require him to deny this (e.g. MacFarland 1970, 106). But he does not deny it. For example, he attends to the complex structure of actual organisms and yet refuses to rule out the possibility that they originate in mere mechanism (5: 400 and $5: 418)$. And he also points out that the remarkable structures of crystal formations seem as if designed and yet are mechanically explicable $(5: 348 ; 5: 419)$. (EE $20: 217-8$ on crystals does not conflict with this, for it concerns not "explanation" or "the possibility of the objects themselves" but rather the "subjective principles of reflection" on objects.)

23 Wright 1976, 24, 81, and $84 \mathrm{ff}$. And (different in some respects) Millikan 1984, ch. 1, especially the definition of "proper function" (28); Neander 1991, 174, and Godfrey-Smith 1994, 347.

24 See Boorse 1976, Nagel 1977, 282-87, and Cummins 1975, 746, for similar criticisms of etiological analyses, and also Sober's (1984, 147-55) additional argument that natural selection does not explain why any particular individual develops as it does but only the make-up of a general population. 
account of the function of hearts in previous organisms of this species. The resulting analysis has a complex two-level structure, according to which teleological notions like function or purpose apply directly to inherited general and repeatable traits, and through them to the parts of individual complex systems. ${ }^{25}$ Kant's analysis, by contrast, neither requires the reproduction of individuals within a species, nor applies to individual parts via repeatable traits. Kant's analysis is far simpler: it is composed entirely terms of two requirements on part/whole relations of a complex system. ${ }^{26}$ Kant certainly does consider the application of his analysis to reproduction within a biological species (5: 371 ). The analysis can be so applied by simply treating the species itself as a complex system. But this will clearly bring with it the very problem under discussion: it will still be the case that the parts of the whole (now the species) cannot have come to be present on account of their effects within this very whole, because they must first be present in order to have those effects at all. Kant himself reasons similarly in $\$ 80$ when contrasting his analysis with alternatives focused on the mechanisms of reproduction and the generation of ever more complicated and well-adapted species. ${ }^{27}$ So while there is an alternative to Kant's analysis, that alternative is controversial, and it does nothing to undermine the argument from Kant's own analysis to intelligent design. It rather makes clear a final crucial premise, namely, (iii) that the proper analysis of teleological judgment can and should be stated in terms of simple conditions on the relations between parts and whole in a complex system.

Kant's connection between the Naturzweck and an origin in a concept or idea follows inexorably from these premises. The second premise requires parts which are present on account of their functions within the whole. Given the first and the third premises, there will be no way this requirement can be met save by an origin in a concept or an idea of the whole and the functions of its parts; for there will be no other way

25 See especially Millikan 1984, ch. 1, on "reproductively established families" and Wright 1976, 88, on general traits or capacities. Boorse's (1976) criticism brings out the pressures on Wright to incorporate more about natural selection into his analysis.

26 See also McLaughlin 1990, 50: "All determinations of the concept of natural purpose that Kant introduces have to do with the relation of part and whole".

27 Kant argues that this cannot provide an alternative account of the purposiveness of living beings, but only "put off the explanation" by raising questions about the original beginning of this historical process (5: 419). I will return to this argument briefly below. 
that the effects of the parts within the whole can precede the presence of those very parts, and so explain how they came to be present within that very system. There is nothing weak or obsolete about this argument. The conclusion can be avoided only by rejecting one or another of the premises, and this would have philosophical costs, to be discussed below.

Kant's point, of course, is not to argue that actual living beings are designed or that there is a designer of nature (5: 399). Quite the opposite: Kant's consistent denial of the possibility of theoretical knowledge beyond the empirical natural world leads him to deny the possibility of knowing actual living beings to be Naturzwecke. If the notion of a Zweck requires an origin in a concept, and if there are no concepts at work in nature independent of minds capable of representing them, then the very notion of a Zweck "implies relation to a cause that has understanding" (5: 393) ${ }^{28}$. So we could know something to be a $Z$ weck only if we could know it to be the product of such an understanding. ${ }^{29}$ And something could be known to be a natural organized being only if known to be the product of an understanding responsible for the design of nature, "an (intelligent) world cause that acts according to purposes" (5: 389; also 5: 400; 5: 410). Our ignorance of any designer of nature prevents us from having insight into any such explanations of nature..$^{30}$ And that means we can never know that living beings (or anything else) really are Naturzwecke. Kant himself summarizes this argument in a clear and concise manner: "purposiveness in nature, as well as the concept of things as Naturzwecke, places reason as a cause into a relation with such things, as the ground of their possibility, in a way which we cannot know through any experience" (EE 20: 234).

28 Though I cannot argue for this here, my view is that Hegel's response to Kant requires (in part) denying that concepts are at work in nature only where represented by a mind, which is why Hegel ties his defense of teleological explanation so closely together in the Science of Logic with his defense of objective concepts (Begriffe) and "the idea" (die Idee).

29 "For we can be conscious of the causality of reason in objects, which on that account are called purposive or Zwecke, only in the case of products of art" (EE 29: 234).

30 See 5: 410 and compare especially Descartes' response to Gassendi's first objection to the fourth meditation. 


\section{Justifying and Limiting Teleological Judgment of Nature}

We can, then, neither know natural beings to be Naturzwecke, nor make any headway with teleological explanation of them. Yet Kant does have something to say for the teleological judgment of living beings: he argues that it is both inevitable and even justified in that it is irreplaceably useful to scientific research.

To begin with, it is the specific character of our experience of living beings which will inevitably suggest teleological judgment to us. We do not experience at once their genesis and development, but only their structure at a given time. And because of the rules which form our experience - the causal principle relating events in time, in particular this structure inevitably appears strikingly contingent to us. This feature is not unique to living beings or due to any special features distinguishing them from artifacts: experience of a living being is akin to seeing a "regular hexagon, drawn in the sand in an apparently uninhabited land" - we "would not be able to judge" this as anything but truly organized (5: 370$)$. Though we believed this land to be uninhabited and nothing here to be the product of design, still our experience of the hexagon itself would suggest that someone created it in accord with an idea of a hexagon. ${ }^{31}$

Furthermore, teleological judgment of living beings is supposed to be irreplaceably useful, but not in virtue of explaining anything. Kant consistently holds that our explanatory insight into nature must always be mechanistic. And we must always attempt to discern mechanistic explanations for everything in nature, even though there can be no guarantee we can complete the task prescribed by this "regulative" principle of mechanism. ${ }^{32}$ Teleological judgment is justified insofar as it plays an indispensable role in this project; it serves as "a heuristic principle for researching the particular laws of nature, even granted that we would want to make no use of it for explaining nature itself" (5: 410).

31 Why can't we learn to experience living beings differently? Because Kant takes the relevant forms of our experience - time and the category of causality - to be not plastic but invariable. And we do continue to think of (e.g.) the heart in teleological terms - to take it to have a specific purpose of its own, in terms of which it might malfunction. See Millikan 1989, Neander 1991, and Ginsborg 2001, 252, on Kant.

32 See especially 5: 383; 5: 387; 5: 410; 5: 418; EE 20: 218. MacFarland 1970, 89-90 (also 35-6, 131), argues that reflective teleological judgment is a "presupposition" necessary to our search for mechanistic explanations. See also McLaughlin 1990, 156-7, and Guyer 2001b, 266. 
To see this indispensable role of teleology in "researching the particular laws of nature," imagine we were to discover a completely unknown artifact with intriguing behavior. Kant holds that our epistemic limitations are such that we can have direct insight neither into what is and what is not a natural kind, nor into which particular empirical generalizations are natural laws. ${ }^{33}$ This raises the threat that we might mistake an utterly unknown and uncomprehended artifact for a yet unknown natural kind. Such a mistake would block any inquiry into the underlying structure of the artifact; for it would suggest instead primitive natural laws specifying that this natural kind has a natural disposition to whatever intriguing surface behavior we observe. Judging it to be an artifact, by contrast, would suggest underlying natural materials were chosen for inclusion because the natural laws governing their behavior generate some specifically desired effects. This might occasion an inquiry into such functions and their overall intended purpose. But it also might occasion a different sort of inquiry, aimed at better understanding the underlying natural materials and the interrelations of the natural laws governing them.

It is precisely this second sort of research project to which are we supposed to be directed by teleological judgment of living beings. Such judgment is justified because, given our epistemic limitations, it alone can prevent us from stalling at the surface presented by living beings, "wandering about figments of natural capacities" (5: 411). Teleological judgment guides us specifically toward trying to understand how smaller and smaller parts of living beings contribute to the functioning of the whole. For example, the "maxim" that "nothing in such a creature is in vain" - or that the parts are present not by chance but in order to fulfill functions - serves as a "guideline" for "observation" directing us away from the surface behavior and specifically toward inquiry into anatomy (5: 376). ${ }^{34}$ The ultimate (though perhaps unreachable) goal of such research is to analyze living beings until we can form empirical concepts fit to classify their parts into natural kinds, and to frame natu-

33 On natural laws see for example 5: 183; on empirical concepts and kinds, see for example EE 20: 212-3. Regarding both see also the "Appending to the Transcendental Dialectic" at A642/B670ff. Compare Ginsborg's different reading of the relevance of these topics to Kant on biology $(2001,246-7)$, and compare also Cummins 1975, 758-9, on functional analysis.

34 Note that this passage ties the idea of "an order of things entirely different form that of a mere mechanism" specifically to "a supersensible determining ground beyond the mere mechanism of nature" - none of which can be the object of theoretical knowledge $(5: 377)$. 
ral laws governing how those parts produce systems with just these capacities. That is, the ultimate goal would be to so improve our grasp on natural kinds and laws that we can understand living beings as mechanistic systems, completely determined by their independent parts. Teleology thus directs or guides us to seek explanations from which teleology itself must be excluded. And we can thus "keep the study of the mechanism of nature restricted to what we can subject to our observation or experiments, so that we could produce it ourselves, like nature, at least as far as the similarity of its laws is concerned" (5: 383). This is the sense in which scientific research into "mechanical explanation" itself requires the "subordination" of mechanism to teleology (5: 417).

Kant's claims for the inevitability and justification of teleological judgment of living beings are often mistaken for a claim that living beings are mechanically inexplicable Naturzwecke. This is especially true of the following well-known passage:

It would be absurd for humans even to make such an attempt to grasp [fassen], or to hope that there may yet arise a Newton who could make comprehensible [begreiflich] even the generation of a blade of grass according to natural laws that no intention has ordered; rather, we must absolutely deny such insight to human beings. (5: 400; emphasis mine)

But the point of this passage is not to rule out the possibility that living beings originate in "mere mechanism"; indeed Kant's next sentence explicitly insists on leaving open that very possibility. The key to this passage is that it carefully avoids any doubts about mechanical explanation (in the objective sense) or Erklärung. What Kant doubts is rather that we can successfully "grasp" (fassen), "understand" or "comprehend" (begreifen) living beings in mechanistic terms, and he explicitly makes his claim relative to our human perspective. The point is that, given our epistemic limitations, 'grasping' living beings in teleological terms is both inevitable and the only hope we have of advancing toward any explanation of them at all - even though such explanation itself could only be mechanistic. ${ }^{35}$

35 Those who take the passage to deny mechanical explicability sometimes see some hope at least for the claim that practical difficulties make it unlikely that such explanation could be possible for us; see McLaughlin 1990, 158, and Wood 1999, 222. But note that Kant's denial is absolute or utter ("schlechterdings"), and he adds that "probabilities count for nothing here" (5: 400). The key features of the above passage are carefully repeated elsewhere: "absolutely no human reason (or even any finite reason that is similar to ours in quality, no matter how much it ex- 
It remains true, however, that teleological judgment always implies teleological explanation, and this is a first reason why such judgment must be severely restricted in status. Kant says:

Teleological judging is rightly drawn into our research into nature, at least problematically, but only in order to bring it under principles of observation and research in analogy with causality according to ends, without presuming thereby to explain [erklären] it. It thus belongs to the reflecting, not to the determining power of judgment. (5: 360)

Teleological judgment always carries explanatory implications which we can never make good upon; so such judgment may be used only "problematically" to guide "observation and research," but never accepted literally into the content of our knowledge of nature. Using Kant's technical terms: in our discursive experience the "determining" power of judgment determines the objects of experience, drawing (for example) on the form of causal judgments and on ordinary empirical concepts. Teleological judgment and the concept of a Naturzweck cannot legitimately play anything like this role. They may be legitimately employed only because of the need for guidance of our "reflecting" power of judgment - only, that is, to guide the process of forming empirical concepts fit to capture natural kinds and frame necessary natural laws. ${ }^{36}$

The preceding points connect to a number of important further philosophical ambitions of the KU which cannot be treated adequately here, in particular: the argument in the two introductions that we also need the guidance of reflective teleological judgment of nature as a whole, and the moral conclusions which later sections draw from that need. ${ }^{37}$ We must instead return to our specific focus on our initial ques-

ceeds it in degree) can ever hope to understand (verstehen) the generation of even a little blade of grass from merely mechanical causes" (5: 409; my emphasis). Guyer 2001b, 275, also correctly recognizes that these passages provide no good reason to rule out the mechanical explicability of living beings; he sees Kant here failing to reach a desired conclusion, whereas I deny that Kant endorses or desires the conclusion which does not in fact follow.

36 On the reflecting power of judgment, see especially EE 20: $211 \mathrm{ff}$. and 5: $179 \mathrm{ff}$.

37 I make no claim to defend here these further ambitions of the KU. Regarding Kant's case for the necessity of reflective teleological judgment of nature as a whole: experience of living beings leads us to judge them in teleological terms, and this in turn leads us to judge nature itself similarly; but this amounts neither to knowledge of organization in nature, nor to an empirical justification of teleological judgment. True, the general principle that nature does nothing in vain "is of course to be derived from experience". But this is so only in the sense that experience of living beings "occasions" the principle. Kant immediately contrasts 
tions concerning teleology, biology and explanation; for we can now understand how Kant consistently holds the views which at first seemed inconsistent. In fact, we have seen how each part of Kant's complex position is supported by arguments anchored in the full-strength organization condition, itself built upon the objective notion of explanation. First, with regard to the question of mechanical explicability, Kant can indeed legitimately answer both 'no' and 'maybe': a true Naturzweck could not be explained in mechanistic terms; actual living beings cannot be known to be Naturzwecke and so we cannot rule out their mechanical explicability. Second, with regard to the justification of teleology applied to living beings, Kant can indeed legitimately answer both 'yes' and 'no': teleological judgment is justified insofar as it sets us an indispensable research project; but when it comes to nature we may not hope for any insight at all into teleological explanation.

\section{Against Weakening the Organization Condition}

Our interpretive success so far, however, makes more pressing still the puzzle concerning the tension between the two requirements built into the concept of a Naturzweck. If the first requirement can be met only with an origin in a concept of the whole system (5: 373), and the point of the second is to rule out external design (5: 373 ), then the two certainly seem to conflict.

As noted above, interpreters generally have tried to read Kant's analysis so that it is free of such a tension between requirements. The most popular proposal is that Kant's first requirement demands only that the whole seems to determine the parts, and this need not conflict at all with the second requirement that the parts really do determine the whole. In other words, Kant is supposed not to endorse the fullstrength organization condition (or premise (ii) in the argument for a connection to intelligent design). The first requirement would then demand no special explanation of the origin of a system, or no special causal history. It would require only a special current structure or form - namely, one which is sufficiently complicated, complex, or regular that it inevitably seems to us as if it were designed. The analysis (says Mac-

this with a justification: there can be no "grounds in experience" (Erfahrungsgründen) for the principle (5:376; see also $5: 378-9)$. The principle is justified only by facts about us - by our need for guidance given our lack of direct insight into natural kinds and laws. See also Kitcher 1986, Horstmann 1989, and Guyer 1990; on the connection to biology specifically, see especially Guyer 2001b. Kant also seeks to draw consequences concerning practical philosophy from the need to judge nature in teleological terms. Here too it is crucial that this is not supposed to require theoretical knowledge that nature is truly organized. On the moral argument, see especially Guyer 2001a. 
Farland) demands "systems whose parts are so intimately inter-related that they appear to depend on a plan of what the whole was to be like"; it does not (Zumbach adds) demand wholes that "literally cause their parts" 38 . And Kant himself can seem to suggest this reading after stating the second requirement: "the idea of the whole" must function "not as a cause - for then it would be a product of art" (5: 373; my emphasis). And, "in such a product of nature each part is conceived [...] as if existing [...] on account of the whole" (5: $373 \mathrm{f}$.).

But this interpretation, while popular, is a decisive mistake. To begin with, Kant's own statement of the first requirement demands specifically systems whose parts themselves "are possible only through their relation to the whole" (5: 373). Contra recent interpreters, Kant does not require systems whose parts are such that our judging them is only possible insofar as we judge them in relation to a whole. ${ }^{39}$ Thus Kant repeats explicitly that the very idea of a $Z$ weck or organized being requires a special "causality of its origin" (5: 369; also 5: 393). And Kant also repeats that the very concept of a Naturzweck also requires a special causal history: "the concept of a thing as a Naturzweck is a concept that subsumes nature under a causality that is conceivable only by means of reason" (5:396; see also EE $20: 234)$. Note that there are two points here: First, the very concept of a Naturzweck requires a special causal history, namely, the organized whole must really determine or bring about the presence of the parts. And, second, the only way such a causality is "conceivable" is "by means of reason." The precise status of this second point and the implications of intelligent design is a complicated matter to be discussed further below. But none of these complications in any way affect or mitigate the status of the first point: the concept of a $\mathrm{Na}$ turzweck simply and directly requires a special causal origin.

Furthermore, this requirement of a special causal origin is not incidental but rather fundamental to Kant's entire discussion of teleology. For this is what grounds

38 MacFarland 1970, 104 (my emphasis); Zumbach 1984, 129 (also 20, 127). Allison sometimes suggests a similar reading, insofar as the analysis is supposed to demand merely systems which "can only be understood" by us in a particular light $(1980,212)$. In some cases the confusion between the constructed concept of a Naturzweck and actual organisms makes this further mistake inevitable: Zumbach 1984, 129, for example, reasons that the analysis cannot possibly require that "wholes literally cause their parts" because then the existence of living beings would require the reality of backwards causation.

39 For a contrasting recent interpretation, see e.g. Zumbach 1984, 20. Note that Kant consistently uses the term "possibility" in this connection to refer to the objective issue of how a system really came about, not the subjective issue of how we must judge. For example, he explicitly distinguishes issues concerning "the possibility of the objects themselves" from those concerning the "subjective principles of reflection" on those objects (EE 20: 217). He speaks of "the real ground" of the "possibility" of a Zweck (5:220), and he denies we can completely rule out a "ground of the possibility" or "generation" of living beings in "mere mechanism" (5: 400). It is clearly in this objective sense of "possibility" that teleological judgment "provides no information about the origination and the inner possibility of these forms" $(5: 417)$ 
the distinction in the KU between Kant's discussions of aesthetics and of teleology. It grounds the contrast between the "subjective formal purposiveness" or "purposiveness without a purpose" of aesthetic judgments, on the one hand, and the "objective purposiveness" of teleological judgments, on the other. The point of the contrast is not that judgments drawing on the concept of a Naturzweck have an objective status or that we can know real Naturzwecke exist - as Kant denies this. ${ }^{40}$ The point concerns rather the content of Kant's two analyses: an aesthetic judgment may imply only that its object has a form which subjectively appears to us as if truly organized, but a teleological judgment implies that the parts of a system objectively are present specifically because of their roles in the whole. ${ }^{41}$

Finally, if we were to remove from the analysis of teleological judgment all explanatory implications about the presence of the parts, then we will contradict nearly every step of Kant's extended argument. First of all, we lose Kant's critique of merely relative purposiveness: the failure of benefit to carry such explanatory implications will no longer affect its fitness as a justification for teleological judgment. Second, it will now be easy to conceive of a system of purely mechanistic origin which is also a true Naturzweck - we need only conceive of a system which inevitably appears designed to us but in fact is not. This would contradict Kant's repeated claim that we cannot even think (denken) or make conceivable how a genuine Naturzweck could be non-designed. ${ }^{42}$ And it would also contradict Kant's claim that we cannot com-

40 Teleological judgments of natural beings can have only a status which is subjective $(5: 391 ; 5: 400)$, not objective $(5: 388 ; 5: 401)$. This limited status is shared by all judgments applying to nature the concept of "objective purposiveness" (EE 20: 236). On this point too, interpreters are led astray by the failure to distinguish the concept of a Naturzweck from the empirical concept organism; Zanetti 1993, 348, for example, interprets "objective purposiveness" in light of the fact that "organisms exist".

41 On "subjective formal purposiveness", see e.g. 5: 190; 5: 228; 5: 361; on objective purposiveness see EE 20: 221; 5: 194; 5: 360. In aesthetic judgment, "purposiveness" is represented "on a merely subjective ground", and in teleological judgment "as an objective ground, as a correspondence of its form with the possibility of the thing itself, in accordance with a concept of it which precedes and contains the ground of this form" (5: 192; my emphasis). Kant's discussion of aesthetic judgment famously introduces "purposiveness without a purpose"; but this is "subjective formal purposiveness" (5: 190), in contrast to the "objective real purposiveness" (5: 193) of teleological judgments and the concept of a Naturzweck. Also, Kant says that, in the case of "objective purposiveness," "judgment is no longer purely aesthetic, i.e. a mere judgment of taste. Nature is no longer judged as it appears as art, but to the extent that it really is art" (5: 311). I thank Ginsborg especially for pressing me on this topic.

42 E.g. 5: 393; 5: 396; 5: 400. Contrast Zumbach 1984, 127: “according to Kant [...] functional descriptions are appropriate to parts of those mechanical systems whose parts are considered to be brought about by the whole". Zumbach, and those who follow him, must use terms like "considered" here to blur Kant's distinction between denken (think) and erkennen (cognize). The distinction allows us to think or conceive many possibilities we cannot empirically cognize. If some- 
prehend how one and the same thing could be both a Zweck and a completely mechanical whole, specifically because "one kind of explanation excludes the other" (5: 412; my emphasis). Finally, the weakened organization condition would leave Kant with no reason for his denials that we can know objects of experience to be Naturzwecke (5: 397; EE 20: 234); such knowledge would merely require identifying those natural systems with a structure which is such as to appear designed to us. ${ }^{43}$

Nor can there be any hope for any alternative interpretation which in some other way relaxes the demand of the first requirement so as to weaken the tie to intelligent design and remove the tension between requirements, as in McLaughlin or Ginsborg. ${ }^{44}$ For the critical difficulties will affect any step away from the full-strength organization condition, no matter how small. The basic problem is that any weaker requirement will fall prey to the argument Kant himself deploys against the idea that merely relative purposiveness justifies teleological judgment. Kant argues as follows: the fact that one thing benefits another does not justify the attribution of purposes, because this benefit might not occur specifically because of any purpose or goal; the benefit itself might be merely accidental. To exclude such accident is to rule out the possibility that the parts are present for some other reason and just happen by chance to benefit the whole by fulfilling specific functions. To rule this out simply is to impose the full-strength organization condition - to require that the parts are present not for some other reason, but specifically because of their functions within the whole. ${ }^{45}$

thing has a structure which we cannot but cognize in our experience in teleological terms, then we might not be able to so cognize it also in mechanistic terms. But that is no impediment to conceiving or thinking that it might in reality not be designed. Compare: we must cognize our behavior as causally determined, but that is no impediment to thinking or conceiving ourselves as free (e.g. Bxxviii).

43 If this reading were correct, then we could even know other things (aside from living beings) to be true Naturzwecke. For example, Zumbach 1981, 72, concludes from his reading of Kant's analysis that "it is clear given his explication of the concept, a social group is a natural purpose"; see also a similar suggestion in McLaughlin 1991, 64. I think the right conclusion is not that Kant misses something which would indeed be so "hard not to notice" (Zumbach 1981, 72) about his own analysis, but rather that Zumbach has misinterpreted the analysis.

44 Ginsborg and McLaughlin advocate versions of a less-demanding first requirement which depart less radically from Kant. They agree in particular that the first requirement carries some implications about causal history, or about why the parts of a system are present. Ginsborg reads the analysis as including the negative requirement that the origin of a Naturzweck must really be such as could not be determined or caused by the basic laws governing the motion of matter alone (2001, 238-43). McLaughlin's version requires more still: it requires specifically a form whole-to-part "efficient causality", but one which is not "a teleological relation at all" $(1990,50)$.

45 Consider McLaughlin's requirement of a non-teleological whole-to-part "efficient causality" $(1990,50)$. But this would allow systems where the parts fulfill functions only as an accidental consequence of such a causality. This is why Kant does, and must, require a specifically teleological relation between whole and part: the parts must be present specifically for the sake of certain of effects: their 
A closely related point is that only the full-strength organization condition can make sense of the normative implications of teleological notions, or the possibility that a part might malfunction or might fail to perform as it ought. As Kant says, "a teleological judgment compares the concept of a product of nature as it is with one of what it ought to be" (EE 20: 240). Now imagine a hexagon traced in the sand which came about by an extraordinary coincidence. And imagine that its sides are very slightly unequal, though still close enough that we could not but judge them as designed to make up a perfect hexagon. Surely our inability to judge otherwise would not make it literally true that the lines making up this purely coincidental hexagon are themselves slightly defective, or themselves ought to be more perfectly equal in length. That a system seems a certain way to us might have consequences concerning how we would wish the system to be, but not consequences concerning how that system itself really ought to be. If the parts themselves are to have specific functions which they ought to fulfill, then it cannot be the case that the connection between part and function is merely apparent from our point of view. To rule this out is again to impose the full-strength organization condition - to require that the parts really are present specifically in order to fulfill specific functions within the whole. ${ }^{46}$

In sum, Kant provides excellent reasons for the full-strength organization condition, which he certainly does endorse: teleological judgment of complex systems implies that the functional organization of the whole really does determine the presence and form of the parts. We will see below that this claim is not challenged by either of the two most prominent contemporary philosophical approaches to the notion of function.

\section{Kant's Second Requirement and the Inexplicability of the Naturzweck}

To understand Kant's analysis and the point of its second requirement, we must reject the assumption that the tension between requirements is a potential defect we should interpret away. The truth is that Kant himself recognizes the tension, and

functions or purposes within the whole. This is made especially clear by EE 20: 236, by Kant's recognition of the normative implications discussed below, and by his emphasis on the house example itself (which McLaughlin 1990, 49, must dismiss, saying it "raises more questions than it answers").

46 I am indebted to Ginsborg's (2001) enlightening stress on Kant's recognition of this normativity, but I do not think her account can make sense of it. She claims that this normativity of functions carries no implication of origins in a concept or of intelligent design because it is "independent of questions about [...] historical origin" (2001, 251). But that cannot be right, because it would allow functions for the parts of merely coincidental wholes. Elsewhere, Ginsborg recognizes the difficulty: she requires "normative regularities" which "do not hold as a matter of sheer coincidence" but are rather "laws governing the structure and functioning of organisms and their organic parts" $(2001,246)$. But that now is to require a special historical origin: one which is non-accidentally governed by norms. 
treats it as a desired conclusion. Most prominently, this tension is Kant's topic in $\S 74$, which focuses on the "inexplicability of a Naturzweck" (5: 395). Here Kant argues that the impossibility of empirical knowledge of Naturzwecke follows from the analysis itself, specifically because of a conflict between the two requirements. That is, the concept of a Naturzweck is "problematic" - its "objective reality" is not "demonstrable" - because of a conflict: "as a concept of a natural product it includes natural necessity and yet at the same time a contingency of the form of the object (in relation to mere laws of nature) in one and the same thing" (5: 396f. $)^{47}$. We could of course change the analysis to eliminate the conflict. But we have been attending to Kant's arguments that the analysis needs just these requirements in order to draw the most important distinctions: the first is necessary to distinguish genuine from merely external purposiveness (as in the sea, sand, and trees); the second is necessary to distinguish systems which by nature or intrinsically would call for teleological judgment from artifacts. Insofar as these requirements are both justified but conflict in a way ruling out knowledge that they can be jointly satisfied, Kant is right to deny that we can know living beings to be Naturzwecke.

Kant goes further still in explaining the point of the second requirement. The point is not to rule out mechanical explicability, as this is guaranteed by the first requirement alone. The point is rather to introduce a conflict which can protect against any intrusion of theology into our empirical knowledge of nature. Given the single order of real causes, the first requirement demands an origin in a concept. But the second requirement redirects the force of the first away from any search for a supernatural intelligent designer, and toward the parts of natural systems themselves - ultimately toward their constituent matter. The two requirements might actually be jointly satisfied if matter itself could represent concepts and organize itself in accordance - if material nature itself were self-designing or self-organizing. But matter cannot do this. Here Kant's analysis justifies more than the merely epistemological conclusion that we can never know whether actual living beings are Naturzweck; it justifies the conclusion that no system exclusively part of material nature could be a Naturzweck at all. ${ }^{48}$ This conclusion is intended by Kant:

47 Or, even if we could have knowledge of an external designer of living beings, precisely this would undercut the sense in which they are natural in the sense of selforganizing: "how could I count things that are definitely supposed to be products of divine art among the products of nature?" (5: 397).

48 I will argue below that Kant's resolution of the antinomy does not back away from this claim. Note that Kant holds not only that matter is not capable of selforganization, but also that empirical matter could not possibly be capable of this. The status of the stronger claim in Kant raises difficult issues about the (supposed) a priori status of the nonetheless empirical concept of matter. See especially Friedman 2001. See also: "the possibility of a living matter [...] contains a contradiction" (5: 394). Note that this is not to say that Kant is analyzing the ordinary notion of life, and declaring it to require mechanical inexplicability. Kant is here arguing against a view which defends "the realism of Naturzwecke" by claiming to find "intentionally acting causes" in matter itself (5: 394; see also 5: 392 ). It is the idea of such intentionally acting causality which is supposed to be 
In teleology we certainly talk about nature as if the purposiveness in it were intentional, but at the same time we ascribe this intention to nature, i.e., to matter, by which we would indicate (since there can be no misunderstanding here, because no intention in the strict sense of the term can be attributed to any lifeless matter) that this term here signifies here only a principle of the reflecting, not of the determining power of judgment. (5: 383 ; also $5: 411)^{49}$

The tension between requirements built into the analysis of the concept of a Naturzweck is designed to compel this conclusion: the analysis cannot be completely satisfied by anything exclusively part of material and empirically accessible nature; so we cannot accept the literal truth of teleological judgments of nature, or presume that they really signify objects; such judgments may be legitimately employed only as a guideline for our research. Thus Kant can protect empirical knowledge of nature from any intrusion of "something which does not belong to physics at all, namely a supernatural cause" (5: 383).

What about Kant's own apparent suggestions that the organization condition must be weakened? Here we must again be careful to distinguish the content of Kant's analysis from his claims about its application. First, consider Kant's comment that the concept of the whole must not figure "as a cause" (5:373). The point is that something which really meets the second requirement could not be literally caused by "the concepts of a rational being outside of it" (5: 373$)$; so it can lead us to teleological judgment not by having such a cause, but only by having a current structure which nonetheless suggests intelligent design. Kant clearly thinks that living beings have the requisite structure. But we must not confuse this point about how experience suggests that we should apply the concept of a Naturzweck with the content of Kant's analysis of that concept. Kant's analysis requires more than such a special structureit requires that the parts really are present on account of their roles in the whole. Only this makes possible Kant's claim that our experience "exhibits" but cannot "prove" the existence of Naturzwecke (EE 20: 234).

Similarly, Kant certainly does conclude that teleological judgment of nature can only be "reflecting judgment," and he sometimes characterizes this limitation using the "as if" locution. But this is a point about the status of judgments applying the concept of a Naturzweck; it is not a point about the content of Kant's analysis. To see the difference, contrast the placement of the "as if" in two very different interpretations:

(a) The concept of a Naturzweck requires only that it seems to us "as if" the whole determines the presence of the parts. Thus there need be no problem with the application of that concept in teleological judgment.

contradicted by the concept of matter. The same point is made by similar passages in Lectures on Metaphysics 29: 275 and Metaphysical Foundations of Natural Science 4: 544.

49 Note that this merely reflective status attaches not just to judgments explicitly invoking intelligent design; it is shared by all teleological judgments of nature, or all judgments drawing on the concept of a Naturzweck (EE 20: 241). 
(b) The concept of a Naturzweck requires that the whole determines the presence of the parts. Thus the application of that concept in teleological judgment must be restricted to an "as if" status.

Interpretation (a) removes all the problematic explanatory implications from teleological judgment of nature. But interpreters who go this route remove as well all reason to limit teleological judgment of nature to a merely "as if" status, leaving them in an awkward position. They must say that Kant has no good reason for the limitation he places on all teleological judgment of nature, or all judgment drawing on the concept of a Naturzweck (EE 20: 241). Kant would have reason to limit only something else: judgments drawing specifically on the concept of design..$^{50}$

The right reading is rather (b). Kant gives one single analysis of teleological judgment of nature, corresponding to one single constructed concept of a Naturzweck. He distinguishes the unjustified use of that concept from the justified use of the very same concept. Put another way, he distinguishes a special limited status to which judgments employing the single concept of a Naturzweck must be restricted. For example:

The concept of an objective purposiveness of nature serves only for the sake of reflection on the object, not for the determination of the object through the concept of a $Z$ weck, and the teleological judgment on the inner possibility of a natural product is a merely reflecting, not a determining, judgment. (EE 20: 236)

Teleological judgment of nature (the application of the concept of the Naturzweck) has such strong explanatory implications that it must be restricted in status to a mere subjective validity, and can be justified only as a guide for "reflection on the object" in our research. Its literal implications need not, and should not, be accepted into the content of scientific investigation of nature. Although it is occasioned by certain experiences, such teleological judgment is not justified in virtue of capturing any truth about the natural world - not even a limited or weaker truth about the current structure of some natural object. Such judgment is justified only in virtue of a truth about us: we have epistemic limitations that leave us in need of guidance by teleological judgment (more specifically, guidance is required by our "reflecting" power of judgment, responsible for forming empirical concepts and framing particular laws of nature.) The resulting merely subjective necessity or validity is compatible with the

50 Probably the most frank about this is Zumbach: he reads Kant as suggesting by "punning" that the concept we may make only non-determining use of is actually the concept of "design" itself $(1984,120)$. Note in addition that the weakened analysis could not serve to guide research: analytic inquiry into initially hidden underlying mechanisms is suggested where it is "as if" nature itself requires the thought 'those parts are present on account of some role within the whole.' The very different thought 'this whole does not literally cause its parts, but merely seems as if it does when viewed from our perspective' would be more apt to inspire research into ourselves and our peculiar perspective. 
possible mechanistic explicability of living beings. It is even compatible with the possibility, which Kant refuses to rule out, that judgments drawing on the concept of a Naturzweck might be literally true of nothing at all..$^{51}$

\section{The Antinomy and Transcendental Idealism}

Kant does offer a sort of resolution of the conflict between the two requirements, specifically in the "Antinomy of the Teleological Power of Judgment". Much of what Kant has to say here depends on his transcendental idealism, and aims to integrate his conclusions concerning teleology and biology with the central commitments of the critical philosophy. Given the monumental systematic issues this raises, there can be no question of a comprehensive interpretation of the antinomy here. ${ }^{52} \mathrm{But}$ it is important to venture far enough to defend my central claims against the consensus of recent interpreters that Kant's solution to the antinomy demotes the status of the connection between the concept of a Naturzweck and intelligent design to a mere "assumption" or "presupposition" 53 .

The line of thought behind the recent consensus is this: We are supposed to make the "assumption" about design on account of the nature of our cognition - because we have a discursive intellect dependent on sensible intuition. The antinomy stresses, however, that this is not the only conceivable type of cognition. We can conceive of, though not know anything about, an "intuitive understanding" - "another (higher) understanding than the human" which would not be merely dependent on sensible intuition but rather enjoy a "complete spontaneity of intuition" (5: 406). If the connection between organization and the need for design follows only from the nature of one among different possible sorts of cognition, then it is supposed to be only an assumption this connection applies to nature, thus removing all reason to doubt the real possibility of a non-designed organized natural being.

This reading begins on the right track, but ends up attributing to Kant conclusions for which he does not and cannot argue. It is true that Kant's argument connecting

51 "One does not know whether one is judging about something or nothing" (5:397; also EE 20: 234). "Nothing is to be decided with regard to the possibility of such things themselves by means of this fundamental principle" (5: 413). And: "it is entirely consistent that the explanation of an appearance [...] be mechanical, while the rule for judging of the same object, in accordance with the subjective principles of reflection on it, should be technical" (EE 20: 218). I think that EE 20: 238 suggests not a different content but that we cannot embrace the literal content of teleological judgment (contrast Ginsborg 1997, 334).

52 For example, I cannot address here the basic systematic question of why consideration of the Naturzweck gives rise to something which is, strictly speaking, an "antinomy" parallel to the others found in Kant's critical writings. On this topic, see McLaughlin 1990; Allison 1991; Zanetti 1993.

53 Zumbach 1984, 12; Allison 1991, 33-4, and Thompson 1995, 445. See also Warnke 1992, 45, and McLaughlin 1990, especially 166-7. 
the Naturzweck and intelligent design ( $\$ 65$; EE 20: 236) requires the key premise that there is a single order of real causes in time - or premise (i) above. And Kant's idealism holds that time is only the form of our sensible intuition, and that the principle demanding a necessitating cause holds only for events in time. So Kant's key premise must indeed be limited in application by its connection to our type of cognition. What this shows is that Kant's argument concerning design would not apply to unknowable, non-spatial-temporal "things in themselves". But this definitely does not demote Kant's key premise (i), or his conclusion concerning design, to the status of a mere "assumption". For it is a cornerstone of the critical philosophy that time and the principle of causality remain constitutive conditions of the possibility of objects of experience. So as long as we focus exclusively on the living beings familiar from our experience - considered exclusively as part of material, empirical nature - Kant's connection between organization and an origin in a concept must remain in force, and will continue to generate a conflict within the analysis of a Naturzweck. ${ }^{54}$

It is true, however, that the antinomy introduces consideration of the intuitive intellect in order to open up the possibility that actual living beings are true $\mathrm{Na}$ turzwecke. It does so by introducing a merely logical possibility - that is, a possibility we can think without contradiction but of which we could never have theoretical knowledge. It opens in particular a logical possibility concerning a "supersensible real ground of nature" or a "thing in itself (which is not an appearance) as substratum" for material nature (5: 409). If space and time are only the forms of our intuition, then such a ground would not be spatio-temporal, and would not be bound by the principle that every event is necessitated by a prior cause. So here true organization wouldn't necessarily require a prior representation of the whole as a separate determining cause. This means that such a supersensible ground might - unlike empirical, material nature - be able to organize itself from within. And this might allow the organization condition to be met without a violation of the second requirement's stricture against systems which are the products of external design. So we can at least think without contradiction the possibility that the living beings we experience are true Naturzwecke. We can do so by thinking of them at once in two different but compatible ways: (i) as phenomenal, material nature "in accordance with mechanical laws," and yet also (ii) as somehow determined or conditioned by a "supersensible real ground" specifically "in accordance with teleological laws" (5: 409).

54 Meerbote 1995 raises a similar worry about McLaughlin's reading in particular. Kant does assign the principle of mechanism a merely regulative status in the antinomy. But this principle is not identical to the constitutive causal principle from the "Second Analogy" in the Critique of Pure Reason (KrV); see McLaughlin 1990, Allison 1991, and Ginsborg 2004. Also, the conceivability of another intellect means that this principle "does not pertain to the possibility of things themselves (even considered as phenomena)" (5: 408; my emphasis). But that will open the possibility that phenomena in material nature might be Naturzwecke only insofar as it means we can consider them as grounded by something nonsensible, and so by something not bound by the constitutive conditions of the possibility of experience. 
I have defended here neither the need for Kant's project in the antinomy, nor the doctrine of transcendental idealism to which Kant appeals. But if Kant is going to seek such a resolution of his two requirements, then he certainly does have good reason to appeal to the idea of an unknowable supersensible ground of nature. For he correctly and consistently sees that his analysis rules out the compatibility of teleology and mechanism as applied to the origin of one single system considered as exclusively part of material nature. What if there is no supersensible ground beyond material nature? What if we are instead "justified in regarding material beings as things in themselves"? Kant is clear: in that case it "would in fact follow" that no material natural being could be a self-organizing Naturzweck - for it would be "impossible" for there to be true organization "without intentional production" (5: 408f.). Similarly, with respect to "one and the same thing" there can be no reconciliation of the two requirements of Kant's analysis: "if there is not to be a contradiction here," we must distinguish from natural phenomena "something which is not empirically cognizable nature (supersensible) and thus is not cognizable at all for us" (5: 396; my emphasis). And teleology and mechanism cannot compatibly apply to "one and the same thing in nature"; for

one kind of explanation excludes the other [...] The principle which is to make possible the unifiability of both [...] must be placed in what lies outside both (hence outside of the possible empirical representation of nature). (5: $411 \mathrm{f}$.) $)^{55}$

Furthermore, Kant's solution here denies us not only knowledge but also comprehension or understanding. We can grasp in positive terms neither the "intuitive understanding" itself (5: 406) nor how the two requirements might be jointly met. If we try to get beyond consideration of merely logical possibility we inevitably bring to bear the necessary conditions of our finite cognition. And this brings the key premise (i) into force, leaving us no way to conceive of organization without an origin in a concept, and so without external design $(5: 393 ; 5: 396 ; 5: 400)$ - thus violating Kant's

55 Perhaps the central problem concerning Kant's idealism is accounting for his apparent ambivalence concerning the transcendental contrast between appearances and things in themselves: sometimes it seems to be a contrast between numerically distinct objects (e.g. A30/B45); sometimes rather a contrast between two ways of considering one and the same thing (e.g. Bxviii-xix note; Prauss 1971 and Allison 1983). While I cannot resolve that problem here, I mean to emphasize that Kant consistently denies that teleology and mechanism in particular can be two ways of considering "one and the same thing in nature". Though I cannot argue the point here, I think this suggests that interpretations or reconstructions of Kant's idealism which rely exclusively on the contrast between two ways of considering one and the same thing do not yield a form of idealism which can do the philosophical work Kant envisions in the KU. A further connection to transcendental idealism is that the concept of a Naturzweck is "problematic" (5:397) in precisely the sense introduced in the $\mathrm{KrV}$ discussion of the concept of a noumenon: "I call a concept problematic that contains no contradiction but that is also, as a boundary for given concepts, connected with other cognitions, the objective reality of which can in no way be cognized" (B310/A254). 
second requirement. In this connection the "Introduction" to the KU compares the role played by of the idea of the supersensible here to its role in Kant's theory of freedom: it allows a "possibility which cannot of course be understood, although the objection that there is an alleged contradiction in it can be adequately refuted" (5: 195) ${ }^{56}$. That is, we can defend the mere logical possibility that living beings are Naturzwecke, but can have no theoretical knowledge or even understanding of that possibility. So whatever the further goals of the antinomy, and whatever the ultimate meaning of the transcendental idealism Kant appeals to, none of this is meant to advance our knowledge or understanding beyond the inexplicability of the Naturzweck, or to introduce a role for teleological explanation in any empirical science of nature.

Finally, these conclusions of the antinomy are crucially important in understanding earlier sections of the KU. For instance, consider Kant's well-known application of his analysis to the example of trees, and the three organic processes of growth, selfmaintenance, and reproduction (5: $371 \mathrm{f}$.). This can seem to presume knowledge that the analysis does truly apply, or that trees and other living beings are truly self-organizing Naturzwecke. And Kant's list of three special organic processes can seem to be meant as an explanation of why actual living beings must be mechanically inexplicable. ${ }^{57}$ But reading in light of Kant's solution to the antinomy reveals a different point. What the passage does claim is that these three organic processes show trees to be unlike artifacts, such as a watch (5: 374): in the case of trees the form of the whole is not merely imposed by an external designer. But the passage does not assert knowledge that this form of the whole organism is truly organized, or that the parts are truly present on account of their roles within the whole. Kant thinks that this inevitably seems to be the case to us. But he also rules out any possibility of our knowing this, or even comprehending it. Kant specifically says here that the possibility of such organization without design "can be conceived without contradiction but cannot be comprehended" (5: 371$)$. So this passage certainly does not explain how actual organisms might be non-designed yet also organized and so mechanically inexplicable. On the contrary, the passage explicitly reminds us that this is a possibility we cannot comprehend at all.

56 As far as we can see, freedom too is "inexplicable (just as is that which constitutes the supersensible substrate of nature)" (5: 196 note). Also, it is important that no particular concept of God can allow us to understand in a positive sense the reconciliation of the two requirements of a Naturzweck. A designer God would violate the second requirement requiring the self-organization of a true Naturzweck (5: 397). But any positive way of thinking of a ground of nature as something other than a designer - as for example in Spinoza - would violate the organization requirement on Naturzwecke: it would "remove their contingency, without which no unity of purpose can be thought (5: 393); see also Baum 1990, Thompson 1995, 449; Allison 2000, 87.

57 E.g. Zumbach 1984, 24-6. 


\section{Contemporary Defenses of Function Explanation in Biology}

There are, to be sure, contemporary approaches available which do cut the tie between the notion of function and intelligent design, and consequently can defend a role for function explanation within biology. But we must not limit ourselves to choosing between either criticizing Kant's approach as obsolete in comparison, or defending Kant's approach by reading it as anticipating contemporary views. Kant's account is fundamentally incompatible with the two most prominent contemporary approaches, but it is not obsolete. In fact, noting the rivalry between these two contemporary approaches, and the difficulties faced by each, can help us to appreciate the philosophical strengths of Kant's contrasting account.

The contemporary "etiological" approach turns on an interpretation of natural selection. This approach agrees with Kant that the notion of function of use in biology is teleological and normative, but argues that natural selection can provide the etiology or causal history which determines such functions for the parts of living beings. As discussed above, this requires building details about reproduction and heritable general traits into the analysis of function, and so rejecting Kant's commitment to a simple analysis governing only part-whole relations within a complex system (or premise (iii) in Kant's argument for a connection to intelligent design).

This contemporary approach has its strengths, but also raises philosophical difficulties. Consider a recently popular example: the perceptual mechanism in a frog which detects the presence of flies to be caught with a snap of the tongue. Does this mechanism have the function of detecting flies? If so, then it would be malfunctioning if triggered by some other sort of insect, no matter how nutritious. Is the function rather to detect any sort of catchable nourishment? If so, it would be malfunctioning if triggered by a diseased and poisonous fly. It can be hard to see how the selection history itself can decide on a determinate characterization of the normative function, because all the details about how the mechanism has been used in the past will always be compatible with different characterizations of its normative function. (Compare Kripke's [1982] well-known point about language: the history of the use of a term will always be compatible with different formulations of the normative rule governing its use.) The difficulty is compounded by the possibility this mechanism has simply played very different roles at different times during the evolution of the species, and perhaps plays a brand new role in the very newest generation of frogs. ${ }^{58}$ Contemporary versions of these worries are in fact flourishing descendents of a complaint already present in the KU. Kant argues that a focus on the history of the development

58 The frog example is used by Fodor $1990,70 \mathrm{ff}$., to argue that an indeterminacy problem undermines attempts to use the teleological notion of function to build a naturalistic account of intentionality in philosophy of mind. See also Millikan's response (e.g. 1993, 125; 2002). The worry about different roles played in different parts of a selection history is stressed by Godfrey-Smith 1994 in his argument that it motivates a modified version of the etiological approach. On the connection to "the Kripke-Wittgenstein paradox," see Millikan 1993, ch. 11. 
of ever more adapted species cannot itself successfully account for determinate teleological functions, but serves only to "put off the explanation" (5: 419).

The alternative approach, also prominent, advocates a non-teleological notion of function, as in Cummins' influential "Functional Analysis" (1975). Cummins essentially endorses Kant's claim that any notion of function which purports to explain the presence of the parts of a complex system will indeed carry implications of designed artifacts. ${ }^{59}$ But Cummins takes this to mean that the notion of function useful in empirical science must not purport to explain the presence of the parts. (That is, he rejects Kant's organization condition, or premise (ii) in Kant's argument for a connection to intelligent design.) The resulting notion of function - or 'Cummins-function' - does not explain how systems came to be formed. Rather, given a complex system with some present capacity of interest to us, Cummins-functions explain by providing an analysis of how the parts currently realize that capacity $(1975,762)$. This is not meant to capture a teleological function of the parts, in the sense of some privileged function for the sake of which each part is supposed to be present (1975, 747 f.). Such functions are, because indifferent to causal origins, perfectly compatible with any sort of purely mechanistic origin. And this sort of function explanation may be argued to be non-reducible to mechanism on grounds that the functions themselves might be realized by multiple different sorts of underlying materials and mechanisms. ${ }^{60}$

This approach too has strengths, but it also raises difficulties. Dropping etiological implications (and Kant's organization condition in particular) results in a notion of function that is indiscriminate. For example, Kant's analysis is founded on a distinction between genuine and merely external purposiveness. Cummins' notion of function is entirely indifferent to that distinction. Even the benefit of sea and sand to the spruce trees, given the right interests on our part, provides perfectly good reason to attribute Cummins-functions to the sand, sea and their parts. ${ }^{61}$ Furthermore, the Cummins-functions which apply to a single system can vary freely with the capacity of interest to us. One well-known example: if we take an interest in the capacity of the human body to die of a disease, this will be perfectly good reason to attribute some surprising Cummins-functions to our organs according to how they contribute to that capacity. So Cummins' analysis (unlike Kant's) cannot help to account for how

59 Cummins 1975, 746: "There is, of course, a sense in which the question 'why is $x$ there?' is answered by giving $x$ 's function [...]. But it seems to me that the question, 'why is $x$ there?' can be answered by specifying $x$ 's function only if $x$ is or is part of an artifact".

60 Cummins stresses multiple realizability at 1976, 764. For two excellent nonreductionist accounts of teleology and biology which nonetheless emphasize the philosophical limitations of multiple realizability considerations, see Papinau 1992, and MacDonald 1992.

${ }_{61}$ Millikan 2002, 119: "Cummins-functions can be contrasted with 'accidental effects' only in the sense of effects that do not help to explain the capacity one has chosen to analyze". See also Millikan's examples of clouds with Cummins-functions $(1993,20)$, and Griffiths 1993, 411, on the Cummins-function of a piece of dirt stuck in a pipe. 
our explanatory interests are guided away from the accidental effects of many different randomly defined chunks of nature, and towards the particular sort of system in which a specific subset of capacities seem to be natural or intrinsic. ${ }^{62}$ Contemporary criticisms tend to stress the related point that Cummins-functions cannot be normative. Just because we take an interest in the capacity of the sea to support the spruce trees, this is no reason to think that the parts of the sea ought to function in this way, so that failure to do so would be a malfunction. And yet the notion of function applicable to living beings can seem to be normative: The heart could have innumerably many different Cummins-function depending on the capacity we choose to analyze. And yet it seems as if the heart itself has a more specific natural function, namely, to pump blood. A heart that stops would no longer have the Cummins-function of pumping blood at all. But we tend to think that a heart which stops still has the same function, and is now malfunctioning. ${ }^{63}$

Kant's interpreters have sometimes wanted to defend him by associating him with this second contemporary approach, or with something like contemporary alternatives to teleology such as "teleonomy" ${ }^{4}$. But Kant's view is very different, and incompatible. Granted, all positions discussed here are similar in that they deny any possible theoretical knowledge of intelligent design in nature. But there are very different ways of proceeding from such a denial. This second sort of contemporary approach reacts specifically by limiting the requirements imposed by the analysis of the notion of function: removing all etiological requirements yields a notion of function with no implications of either teleology or intelligent design. Kant proceeds in the opposite manner. He does not limit or weaken the content of his analysis of the no-

62 As Cummins himself says: "no matter which effects of something you happen to name, there will be some activity of the containing systems to which just those effects contribute" $(1975,752$; Millikan 2002, 118). The disease example is discussed by Griffiths 1993, 411. Cummins 1975, 764, responds to a worry that this indiscriminateness renders his functional analysis trivial. But he recognizes the indiscriminateness: nothing about functions guides our interests specifically toward the heart's capacity to pump blood; we single this out only because we happen to already be interested in "the circulatory system's capacity to transport food, oxygen, wastes, and so on" $(1975,762)$. The indiscriminateness is also the root of some difficulties with the use of such a notion of function to generate a functionalist approach to the philosophy of mind; see Sober 1985.

63 We might think it worth capturing the normative notion in our analysis, even if we deny the possibility of knowledge that anything natural really answers to that notion (as Kant does). Cummins himself rules out malfunction insofar as he claims that having a function means being able to perform it $(1975,757)$. See also Cummins on the heart in the previous note. Those with etiological accounts stress this complaint: Millikan 1989, 294, Neander 1991, 181.

64 Zumbach 1984, 129 and also 20, effectively reads Kant in this way, insofar as he denies that Kant's analysis has implications concerning the origin of a system. See also McLaughlin's contrast between function-explanation and teleology, and his claim that Kant's interest is not in "a teleological relation at all" $(1990,50)$. Warnke 1992 in particular emphasizes a claimed similarity between Kant's analysis and "teleonomy" (also Düsing 1990, 142). 
tion of function or purpose; he instead limits the status of judgments applying that notion. It should be no surprise that the resulting notion of function or purpose is very different: Kant's notion is teleological, normative and discriminates between merely external and genuine purposiveness; Cummins' notion is non-teleological, non-normative, and indiscriminate in this respect.

Some also see in the second contemporary approach a reason to think that Kant does (or should) defend a form of teleological explanation of living beings. The idea is to read Kant as denying that teleology can "explain" only in a special narrow and technical sense that teleology cannot deduce the structure of a system from general exceptionless causal laws and prior conditions. But if teleology is supposed to be completely indifferent to such causal origins, then Kant might still be defending a distinct role for teleology in biology, one we could recognize as legitimately explanatory (even if not in Kant's narrow sense of deductive causal explanation). ${ }^{65}$ But this line of thought is also mistaken. Kant may well endorse some such narrow conception of explanation generally, but it does not drive this argument. What drives the argument is an independent claim about teleology in particular: capturing a teleological and normative notion of function requires an analysis which imposes constraints on, and is not indifferent to, the causal history of a system. We saw above that this claim is well-supported by Kant's own arguments. You cannot simply decide, because both appear attractive in different ways, to combine the teleological and normative notion of function with an indifference to causal origins or etiology. And this point is affirmed by the contemporary debate about functions; both sides generally agree that removing the etiological implications yields not a defense of a non-reducible form of teleological explanation but something very different: a non-teleological and non-normative notion of function. ${ }^{66}$

Kant's approach has its peculiarities, to be sure, but one thing it can do is combine the primary advantages claimed on behalf of both contemporary approaches: it can combine (i) recognition of the inevitability and scientific importance of a normative and teleological notion of function, with (ii) critical doubts that we can know that such a teleological and normative notion really applies to nature itself. Some will see a large cost for Kant in any conceptual connection to the idea of intelligent design,

65 Zumbach (especially 1984, 123) advocates this approach. Ginsborg takes Kant to argue for a role for a normative notion of teleology with no implications about causal history $(2001,251)$, though she remains consistent with Kant's usage and so does not call this role "explanatory".

${ }^{66}$ Cummins 1975 draws on this claim in arguing that, because teleology has unacceptable implications, the analysis of the scientifically useful notion of function cannot be etiological. Proponents of the etiological analysis draw on the same claim to generate complaints about the resulting Cummins-functions being nonnormative (Millikan 1989, 294; Neander 1991, 181). Those who advocate combining the advantages of each analysis do not aim to blur the distinction between them, but rather to make appropriate but different use of each; see e.g. Griffiths 1993 use of Cummins' analysis to build what is nonetheless an alternative formulation of an etiological analysis. 
though it is unclear why this should be a drawback given that Kant's point is to deny all possibility of theoretical knowledge of intelligent design. Perhaps the most general problem is rather that this leaves Kant in a complicated and difficult position: he must defend an essential role in empirical science for a concept (Naturzweck) whose application to nature can never itself be the object of empirical knowledge. Many will see an additional cost in any connection to Kant's transcendental idealism. But these are, at very worst, philosophical costs - not reason to think that progress in the biological sciences has rendered Kant's position simply obsolete. While I have made no attempt here at a final comparative weighing of the costs and benefits of each approach, I have shown that Kant supports his conclusions and highlights the advantages of his position (difficult though it may be) with a tightly unified series of philosophical arguments. Departing from Kant's conclusions requires rejecting one or another of his premises. Where contemporary approaches reject these premises, this generates very real philosophical difficulties - difficulties akin to those Kant himself seeks to avoid. So contemporary comparisons do not suggest obsolescence. They point to some surprising and enduring philosophical strengths of Kant's very different approach to teleology, biology, and explanation. ${ }^{67}$

Allison, H. E. 1980. “Kant's Critique of Spinoza”. In The Philosophy of Baruch Spinoza. Ed. Richard Kennington, Washington, 199-227.

-. 1983. Kant's Transcendental Idealism. New Haven.

-. 1991. "Kant's Antinomy of Teleological Judgment". Southern Journal of Philosophy 30 (Supplement): 25-42.

-. 2000. "Is the Critique of Judgment 'Post-Critical'?" In The Reception of Kant's Critical Philosophy: Fichte, Schelling, and Hegel. Ed. S. Sedgwick. Cambridge/ New York, 78-92.

Baum, M. 1990. "Kants Prinzip der Zweckmäßigkeit und Hegels Realisierung des Begriffs". In Hegel und die Kritik der Urteilskraft. Ed. H. F. Fulda / R. P. Horstmann. Stuttgart, 158-173.

Boorse, C. 1976. "Wright on Functions". The Philosophical Review 85: 70-86.

Cummins, R. 1975. "Functional Analysis". Journal of Philosophy 72: 741-765.

Düsing, K. 1990. "Naturteleologie und Metaphysik bei Kant und Hegel”. In Hegel und die Kritik der Urteilskraft. Ed. H.-F. Fulda / R.-P. Horstmann. Stuttgart, 141-157.

67 This paper has benefited greatly from all of the following: comments from and discussion with Michael Forster, Hannah Ginsborg, Desmond Hogan, David McNeill, Adrian Piper, Robert Pippin, Houston Smit, Richard Velkley, Candace Vogler, Rachel Zuckert and two very helpful anonymous referees; comments on related work from Willem deVries and Allen Wood; presentation to the faculty colloquium at Yale and also a group meeting of the North American Kant society at the Pacific American Philosophical Association; and conversations with the students in my Spring 2003 seminar on the KU at Yale. 
Fodor, J. A. 1990. A Theory of Content. Cambridge, Mass.

Fricke, C. 1990. "Explaining the Inexplicable. The Hypotheses of the Faculty of Reflective Judgment in Kant's Third Critique". Nous 24: 45-62.

Friedman, M. 2001. "Matter and Motion in the Metaphysical Foundations and the First Critique: The Empirical Concept of Matter and the Categories". In Kant and the Sciences. Ed. E. Watkins. New York, 53-69.

Garrett, D. 1999. "Teleology in Spinoza and Early Modern Rationalism". In New Essays on the Rationalists. Ed. J. Gennaro / C. Huenemann. Oxford.

Ginsborg, H. 1997. "Kant on Aesthetic and Biological Purposiveness". In Reclaiming the History of Ethics: Essays for John Rawls. Ed. A. Reath, B. Herman, and C. Korsgaard. Cambridge, 329-360.

-. 2001. "Kant on Understanding organisms as Natural Purposes". In Kant and the Sciences, Ed. E. Watkins. Oxford/New York, 231-258.

-. 2004. "Two Kinds of Mechanical Inexplicability in Kant and Aristotle". Journal of the History of Philosophy 42: 33-65.

Godfrey-Smith, P. 1994. "A Modern History Theory of Functions". Nous 28: 344-362.

Griffiths, P. E. 1993. "Functional Analysis and Proper Function". British Journal for Philosophy of Science 44: 409-422.

Guyer, P. 1990. "Reason and Reflective Judgment: Kant on the Significance of Systematicity". Nous 24: 17-43.

-. 2001a. "From Nature to Morality: Kant's New Argument in the 'Critique of Teleological Judgment"'. In Architektonik und System in der Philosophie Kants. Ed. H. F. Fulda / J. Stolzenberg, Hamburg, 375-404.

-. 2001b. "Organisms and the Unity of Science". In Kant and the Sciences, Ed. E. Watkins. Oxford/New York, 259-81.

Horstmann, R. P. 1989. "Why There Has To Be A Transcendental Deduction In Kant's Critique Of Judgment". In Kant's Transcendental Deductions. Ed. E. Förster. Stanford, 157-176.

Kitcher, P. 1986. "Projecting The order Of Nature". In Kant's Philosophy Of Physical Science. Ed. R. E. Butts. Dordrecht, 201-235.

Kripke, Saul A. 1982. Wittgenstein on Rules and Private Language. Oxford.

Macdonald, G. 1992. "Reduction and Evolutionary Biology". In Reduction, Explanation and Realism. Ed. D. Charles / K. Lennon. Oxford.

MacFarland, J. D. 1970. Kant's Concept Of Teleology. Edinburgh.

McLaughlin, P. 1990. Kant's Critique Of Teleology In Biological Explanation. Lewiston.

-. 1991. "Newtonian Biology and Kant's Mechanistic Concept of Causality". In Akten des Siebenten Internationalen Kant-Kongresses, Kurfürstliches Schloß zu Mainz, 1990. Band II, 2. Ed. G. Funke. Bonn/Berlin, 57-66.

Meerbote, R. 1984. "Kant on the Nondeterminate Character of Human Actions". In Kant on Causality, Freedom and Objectivity. Ed. W. A. Harper and R. Meerbote. Minneapolis.

-. 1995. Review of P. McLaughlin, Kant's Critique of Teleology in Biological Explanation (1990). Kant-Studien 86: 470-473. 
Millikan, R. G. 1984. Language, Thought and Other Biological Categories. Cambridge.

-. 1989. "In Defense of Proper Functions". Philosophy of Science 56: 288-302.

-. 2002. "Biofunctions: Two Paradigms". In Functions: New Readings in the Philosophy of Psychology and Biology. Ed. R. Cummins, A. Ariew and M. Perlman. Oxford.

Nagel, E. 1977. "Teleology Revisited”. Journal of Philosophy 74: 261-300.

Neander, K. 1991. "Functions As Selected Effects". Philosophy of Science 58: $168-84$.

Papineau, D. "Teleology and Irreducibility". In Reduction, Explanation and Realism. Ed. D. Charles / K. Lennon. Oxford.

Sober, E. 1985. "Panglossian Functionalism and the Philosophy of Mind" Synthese 64: 165-94.

-. 1984. The Nature of Selection. Cambridge.

Warnke, C. 1992. "'Naturmechanismus' und 'Naturzweck': Bemerkungen zu Kants Organismus-Begriff”. Deutsche Zeitschrift für Philosophie 40: 42-52.

Wood, A. 1999. Kant's Ethical Thought. Cambridge.

Wright, L. 1976. Teleological Explanations: An Etiological Analysis Of Goals and Functions. Berkeley.

Zanetti, V. 1993. "Die Antinomie der teleologischen Urteilskraft". Kant-Studien 84 341-355.

-. 1995. "Teleology and the Freedom of the Self". The Modern Subject. Ed. K. Ameriks / D. Sturma. Lanham, 47-63.

Zuckert, R. 2000. Purposiveness, Time, and Unity: A Reading Of The "Critique Of Judgment". Ph.D. diss., University of Chicago.

Zumbach, C. 1981. "Kant's Argument for the Autonomy of Biology". Nature-andSystem 3: 67-79.

-. 1984. The Transcendent Science. Kant's Conception Of Biological Methodology. The Hague. 